\title{
Características da força de trabalho médica na Província de Cabinda, Angola
}

\author{
Characteristics of the medical workforce in \\ the Province of Cabinda, Angola
}

\author{
1 Escola Nacional de Saúde \\ Pública Sergio Arouca, \\ Fundação Oswaldo Cruz, \\ Rio de Janeiro, Brasil. \\ Correspondência \\ E. Artmann \\ Departamento de \\ Administração e \\ Planejamento em Saúde, \\ Escola Nacional de Saúde \\ Pública Sergio Arouca, \\ Fundação Oswaldo Cruz. \\ Rua Leopoldo Bulhões 1480, \\ sala 710 , Rio de Janeiro, $R J$ \\ 21041-210, Brasil. \\ artmann@ensp.fiocruz.br
}

\begin{abstract}
This article presents the results of a study on the public health system's medical workforce in the Province of Cabinda, Angola. The objective was to study the characteristics of medical personnel, seeking to help define strategies to expand access and improve quality of care. The study covered the period from 2001 to 2004 and used secondary data, semi-structured interviews with health professionals, direct observation, and comparison with the literature. Quality of medical care in Cabinda was low, with one physician per 3,356 inhabitants. There were communities with more than 35,000 inhabitants and not a single physician. Working conditions were poor, and physicians suffered from low motivation. The study concluded that formulation and implementation of policies envisioning improvements in the management of medical professionals in the sector could help enhance the quality of care in the Province, but it would require involvement by relevant actors and additional research on the other health professions.
\end{abstract}

Health Personel; Health Personel Management; Quality of Health Care
Miguel dos Santos de Oliveira 1

Elizabeth Artmann 1

\section{Introdução}

A crise da força de trabalho em muitos dos países mais pobres é caracterizada por graves carências, combinações inadequadas de habilidades e lacunas nas coberturas dos serviços de saúde. Quase todos os países sofrem com a má-distribuição caracterizada pela concentração urbana e os déficits rurais, mas esses desequilíbrios são talvez mais perturbadores a partir de uma perspectiva regional. A região Africana, por exemplo, tem $24 \%$ da carga global de doenças, mas com apenas $3 \%$ dos trabalhadores mundiais de saúde, e responde por menos de $1 \%$ dos desembolsos mundiais com a saúde. O êxodo de profissionais capacitados em meio a tantas necessidades de saúde não atendidas coloca a África no epicentro da crise global da força de trabalho da área de saúde 1. Destacam-se particularmente a escassez e/ou má distribuição de profissionais médicos, o que, em grande medida, contribui para a má qualidade de assistência sanitária às populações ${ }^{2}$.

A Província de Cabinda, objeto do estudo, situa-se no Norte de Angola, país localizado na região austral do continente africano. O sistema nacional de saúde de Angola é constituído pelo Serviço Nacional de Saúde (SNS) tutelado pelo Ministério da Saúde (MINSA), e por todas as entidades públicas, privadas e profissionais que desenvolvem atividades de promoção, prevenção e tratamento na área da saúde 3 . Em geral, a pres- 
tação de serviços no SNS é de baixa qualidade, devido, entre outros condicionantes, à retração dos serviços por falta de segurança, destruição ou saque e abandono do pessoal no interior do país e insuficiência de recursos financeiros. Observa-se ainda a desmotivação do pessoal tendo em conta os baixos salários, carência de formação continuada, insuficientes condições de trabalho e distribuição desequilibrada do pessoal entre as zonas rurais e urbanas, entre as diferentes regiões e entre as diferentes categorias das instituições de saúde 4 .

Cerca de $60 \%$ da população angolana encontram-se ainda concentrados nos grandes centros urbanos 5, resultado da guerra que assolou o país desde a independência, em 1975 até 2002. No momento da realização do estudo, persistia ainda alguma instabilidade político-militar na província.

Cabinda tem uma superfície de $7.270 \mathrm{~km}^{2}$, com 228.233 habitantes 6, tendo cada um dos seus quatro municípios duas comunas. Em muitas unidades de saúde no interior, a presença do médico ainda não é uma realidade por dificuldades de recrutamento, colocação e retenção. Na prática cotidiana, os médicos, muitas vezes, são substituídos por técnicos médios ou básicos de enfermagem.

Apesar de a província dispor de três núcleos de Ensino Superior, nenhum deles oferece cursos de graduação em medicina. A indefinição da política de bolsas interna faz com que os interessados sejam obrigados a recorrer a recursos financeiros próprios, seja no exterior do país ou nas duas faculdades de medicina do país (uma pública e uma particular), ambas localizadas na capital Luanda, onde o acesso é muito difícil, devido à escassez de vagas. Muito irregularmente, o governo de Cabinda tem concedido bolsas de estudos para algumas especialidades profissionais de que carece, devendo os beneficiários cumprir no mínimo dois anos de serviço na província.

Em termos epidemiológicos, Cabinda, à semelhança de todo o país, caracteriza-se por altos índices de natalidade, fertilidade, mortalidade infantil e geral e de incidência e prevalência de doenças transmissíveis, como malária, doenças diarréicas agudas, sarampo etc. ${ }^{2}$.

O estudo objetivou conhecer as características dos profissionais médicos, suas condições de trabalho e contribuir com sugestões para elaboração de estratégias do seu planejamento e gestão, além de fornecer subsídios para estudos posteriores sobre a temática.

O estudo com os profissionais médicos justifica-se pelo seu papel preponderante no diagnóstico e tratamento de doenças, sendo sua ausência em determinado local causadora de grandes constrangimentos como os verificados em Cabinda. Entre eles, transferências constantes dos pacientes para as unidades de referência e dispêndio pelo governo de avultados recursos financeiros com a contratação de médicos estrangeiros que nem sempre se adaptam bem às condições sócio-culturais locais.

As propostas apresentadas basearam-se nos resultados do estudo, bem como na discussão presente na literatura sobre $\mathrm{o}$ assunto 7,8,9,10,11.

\section{Estratégia metodológica}

O estudo abrangeu o período de 2001 a 2004. Os profissionais-alvo foram os médicos do subsistema público da província onde encontra-se a grande maioria, incluindo os estrangeiros não residentes (expatriados).

Para o alcance dos objetivos procedeu-se à análise documental (relatórios da Direção Provincial da Saúde de Cabinda - DPSC; do Departamento Provincial dos Recursos Humanos - DPRH; Gabinete do Plano e Estatística, do Conselho de Administração do Hospital Central de Cabinda - HCC e; das seções municipais), com a finalidade de levantar informações sobre a alocação, rotação/rotatividade, alunos em formação em medicina, regime salarial de médicos, situação epidemiológica e capacidade instalada.

Outros dados quantitativos sobre a população e formandos em medicina com o apoio do governo da província foram obtidos junto ao Gabinete de Estudos Planejamento e Estatística (GEPE).

Foram entrevistados gestores da DPSC, do HCC, unidade de referência provincial, responsáveis municipais da saúde e profissionais médicos do setor. O critério de escolha dos últimos foi o de representatividade, ou seja, os que estavam há mais tempo na província e portanto, conheciam mais profundamente a situação de saúde, aliado ao desejo de participar da pesquisa. O roteiro de entrevista buscou responder questões sobre motivação (considerada a expressão dos motivos de interesse na alocação), produtividade, rotatividade, rotação (transferências temporárias para os municípios do interior, ciclicamente), condições de trabalho (existência de equipamentos laboratoriais e radiológicos básicos de diagnóstico, de medicamentos e insumos médicos e quantidade e qualidade dos espaços físicos de atendimento e internação) e capacidade de resposta dos serviços no tocante à qualidade. As entrevistas foram gravadas e transcritas, tendo os entrevistados assinado os respectivos formulários. O questionário, entretanto, foi respondido por escrito, por opção do entrevistado. 
Os dados de identificação levantados nas entrevistas foram agrupados por categorias com o propósito de se definir o perfil dos entrevistados, e foram considerados de forma individual para fins de associação e interpretação das entrevistas como um todo.

As respostas foram analisadas a partir de algumas categorias previamente definidas como qualificação, motivação, condições de trabalho e remuneração e de outras que foram incorporadas ao longo da pesquisa, como por exemplo, as sugestões para melhorar o quadro da saúde na província.

A associação dos estudantes da província na Universidade Piaget, em Luanda, foi também uma fonte importante para apurar informações concernentes aos alunos em formação em medicina naquela universidade, com o apoio do governo da província, bem como as páginas da Internet da Organização Mundial da Saúde (OMS; http://www.who.int/en/), da União Européia (http:/ / europa.eu/) e da Organização das Nações Unidas (ONU; http:/ / www.un.org/) para os dados demográficos e epidemiológicos sobre Angola.

Paralelamente às entrevistas, utilizou-se a técnica de observação direta com dois deslocamentos do pesquisador à Cabinda, com 15 dias de duração cada, o que permitiu visitar as principais unidades sanitárias e coletar informações que contribuíram na análise dos dados.

A pesquisa levou em consideração as referências éticas da Resolução $n^{\circ}$. 196/96 do Conselho Nacional de Saúde do Brasil.

\section{Resultados}

Situação dos recursos humanos médicos e infra-estruturas de saúde

Na rede pública de saúde de Cabinda, durante o período do estudo, estavam colocados 62 médicos. Deste número fazem parte médicos nacionais (especializados ou não), estrangeiros residentes (congolenses) e especialistas estrangeiros não residentes (expatriados), vietnamitas, cubanos, russos e portugueses.

Do total referido, apenas 21 são nacionais e destes somente quatro são especializados: um em cirurgia; dois em ginecologia e obstetrícia e um em cirurgia maxilo-facial. Parte importante $(28,5 \%)$ dos médicos nacionais, para além do seu papel clássico de diagnóstico e terapêutica, também se ocupa do gerenciamento das instituições e $19 \%$ encontram-se no exterior, em formação.

Na região trabalham também médicos no subsistema militar, os quais não foram objeto de análise do estudo, considerando o seu baixo impacto no atendimento da população, bem como seis exclusivamente no subsistema privado, representando 8,8\% dos 68 médicos civis da província (Tabela 1). Por beneficiarem-se dos mesmos direitos, no grupo dos médicos nacionais se enquadram os médicos estrangeiros residentes num total de seis, sendo três em exclusividade no subsistema privado.

Assim, existe em Cabinda um grande déficit de médicos, com uma estimativa global de 1 médico para 3.356 habitantes, verificando-se em alguns municípios a proporção de 1 médico para 34.521 habitantes.

Quando se observa a colocação dos médicos se constata que a grande maioria se concentra na capital da província (município sede), nomeadamente no HCC e nos cinco centros de saúde aí localizados (Tabela 2).

A concentração de médicos no HCC se explica por este ser o hospital de referência, com os serviços internos de diagnóstico mais diferenciados e com possibilidade de troca de experiência entre médicos e pelo não funcionamento das estruturas de saúde em rede.

Quanto ao regime contratual dos expatriados, identificaram-se três modalidades de contratação: (a) através do MINSA (convênio entre países), (b) contratos individuais com o governo da província e (c) sub-contratos com empresas contratadas para procederem à gestão do HCC. O primeiro grupo tinha como incentivos complementares a moradia gratuita e o subsídio de horas extras; o segundo, apenas a moradia; e o último, transporte coletivo, segurança, refeições e alojamento gratuitos, viagens de férias e seguros O salário dos profissionais estrangeiros variava de 1.466,00 dólares americanos (US\$), para o primeiro grupo, 1.532,00 para o segundo e $2.500,00$ $5.000,00$ para o terceiro 2 .

Os médicos nacionais eram colocados nas províncias através de um modelo único de contrato com o MINSA. Ultimamente passou a ser através de concurso público.

O salário do profissional angolano oscilava de 58.651,20 Kwanzas (Kzs; moeda nacional angolana) equivalente a 733,14 US\$ para interno geral; 102.639,60 Kzs (1.282,99 US\$) para médico assistente graduado e 109.303,40 Kzs (1.366,00 US\$) para o graduado ${ }^{2}$. Assim, o médico especialista estrangeiro com contrato com o MINSA tem, praticamente, o mesmo salário que o especialista angolano.

Entretanto, verificava-se com freqüência o atraso do mesmo paradoxalmente para os que recebiam menos, ou seja, médicos nacionais e estrangeiros com contrato com o MINSA

Merece também destaque a indefinição de aspectos concernentes à capacitação e formação 
Médicos das redes pública e privada (civis) de Cabinda, Angola, no período de 2001 a 2003.

\begin{tabular}{|c|c|c|}
\hline Médicos & $\mathbf{n}$ & $\%$ \\
\hline \multicolumn{3}{|l|}{ Rede pública } \\
\hline \multicolumn{3}{|l|}{ Nacionais } \\
\hline Angolanos & 18 & 26,5 \\
\hline Estrangeiros residentes & 3 & 4,4 \\
\hline Subtotal & 21 & 30,9 \\
\hline \multicolumn{3}{|l|}{ Estrangeiros } \\
\hline Contratados pelo Ministério da Saúde e pelo governo da província & 6 & 8,8 \\
\hline Contratados por empresas gestoras do Hospital Central de Cabinda & 35 & 51,5 \\
\hline Subtotal & 41 & 60,3 \\
\hline Total & 62 & 91,2 \\
\hline \multicolumn{3}{|l|}{ Rede privada } \\
\hline \multicolumn{3}{|l|}{ Nacionais } \\
\hline Angolanos & 3 & 4,4 \\
\hline Estrangeiros residentes & 3 & 4,4 \\
\hline Subtotal & 6 & 8,8 \\
\hline Total geral & 68 & 100,0 \\
\hline
\end{tabular}

Fonte: Oliveira 2

Tabela 2

Alocação dos médicos na rede pública da província.

\begin{tabular}{|c|c|c|c|c|c|}
\hline \multirow[t]{2}{*}{ Médicos } & \multicolumn{2}{|c|}{ Especializados } & \multicolumn{3}{|c|}{ Não especializados } \\
\hline & $\begin{array}{c}\text { Hospital Central } \\
\text { de Cabinda }\end{array}$ & $\begin{array}{l}\text { Município do } \\
\text { interior * }\end{array}$ & $\begin{array}{c}\text { Hospital Central } \\
\text { de Cabinda }\end{array}$ & $\begin{array}{l}\text { Município } \\
\text { sede }\end{array}$ & $\begin{array}{c}\text { Município do } \\
\text { interior }\end{array}$ \\
\hline Nacionais & 4 & - & 14 & 2 & 1 \\
\hline Estrangeiros & 41 & 1 & - & - & - \\
\hline
\end{tabular}

Fonte: Oliveira 2

* Três municípios do interior.

nos distintos níveis. Os cursos de curta duração nas unidades sanitárias, no exterior da província e também os de pós-graduação não são extensivos aos profissionais alocados no interior da província.

Constatou-se a existência de alunos da província em cursos de graduação em medicina na capital e no exterior do país. Contudo, restringiu-se o levantamento aos alunos bolsistas (com apoio parcial ou total do governo de província), dada a obrigatoriedade de estes regressarem à província após a conclusão da formação.

Assim, a província tinha, no período estudado, 15 bolsistas (com apoio parcial) na capital do país, graduandos em medicina e quatro pós-gra- duandos (com apoio total) no exterior do país 2. Os últimos são médicos alocados na província, que mantinham o vínculo com a DPSC continuando com os seus salários normais. Quanto aos graduandos, apenas três se enquadram nestas condições. Os outros 12 ainda não têm qualquer vínculo empregatício na província.

Considerando que a gestão de recursos humanos (RH) refere-se não só às práticas e às políticas necessárias para conduzir os aspectos relacionados às pessoas no trabalho de gerenciamento, mas também ao oferecimento de um ambiente bom e seguro de trabalho 7 e tendo em conta que a acessibilidade aos serviços de saúde é um dos componentes da qualidade do cuidado 12 , 
foi feito também o levantamento das condições infra-estruturais da rede pública de saúde e da capacidade instalada.

Constatou-se que a rede pública de saúde era constituída por 111 estruturas sanitárias (hospital provincial e hospitais municipais, clínicas, centros e postos de saúde). Do total, $47,7 \%$ encontravam-se em bom estado de conservação física, $22,5 \%$ razoável e $29,7 \%$ ruim, encontrandose fechadas 2 . Os elementos considerados nesta classificação foram: a condição da estrutura física, nomeadamente, o estado de conservação de paredes, cobertura, portas e janelas, rede elétrica, instalações sanitárias, rede de esgotos, pintura e a operacionalidade do seu equipamento. A referida rede dispõe de cerca de 370 leitos (para todos os serviços), sendo 255 no Município de Cabinda, 40 em Cacongo, 40 em Buco-Zau e 35 em Belize, nas respectivas sedes municipais. A média provincial é de 1,6 leitos por mil habitantes, cifra aquém das necessidades, considerando que foi observada, em alguns serviços hospitalares inclusive no HCC (na pediatria e ginecologia), a internação de mais de um paciente por leito.

Em síntese, os problemas identificados foram: insuficiência de médicos, sua pouca motivação, ausências freqüentes do local de trabalho, inclusive quando de plantão, visitas rápidas aos doentes internados considerando o multi-emprego, baixa qualificação profissional, sua concentração no HCC, dificuldades de alocação e retenção dos mesmos nos municípios e seu pouco comprometimento com os objetivos da instituição. Os expatriados se encontram nas instituições por um período de tempo muito curto ( 1 a 3 anos) ou, por vezes, com contrato de trabalho dependente de outras instituições. Destacam-se ainda as deficientes condições de trabalho e dificuldades de acesso da população ao atendimento médico.

\section{Opinião de médicos e gestores}

A opinião dos médicos e gestores foi considerada de extrema importância por conhecerem profundamente a rede estudada e por serem os atoreschave. Foram entrevistados os dois gestores de nível provincial; três dos quatro gestores de nível municipal, dado que o quarto tinha abandonado a província dias antes da data marcada para a entrevista, alegando como motivos as deficientes condições de trabalho e sociais; e sete médicos incluindo um expatriado. A limitação a apenas um médico expatriado deve-se ao fim do contrato da empresa que geria o hospital e saída do seu coletivo de médicos, restando na província naquele momento, apenas médicos nacionais e estrangeiros com contrato com o governo local. Assim, foi feita a entrevista com o de maior tem- po de permanência na província e que apresentava grande inserção na comunidade local.

A grande maioria dos entrevistados expressou-se satisfeita com a sua alocação. Apenas um manifestou-se negativamente por trabalhar no mesmo centro de saúde há mais de sete anos e enfrentar enormes dificuldades materiais e organizacionais. Contudo, preferia continuar a trabalhar num dos centros de saúde porque teria mais tempo livre e não teria conflitos com outros médicos, por ser ele o único.

Os profissionais entrevistados não têm qualquer plano imediato para outro emprego. O salário não satisfaz a nenhum médico nacional nem aos gestores de nível municipal. A exigüidade de salários obriga os médicos e até os gestores de nível provincial a adotar o regime de empregos múltiplos (multi-empregos). A adoção do referido regime é impensável nos municípios do interior tendo em conta a incipiente organização dos serviços e setores e as dificuldades econômicas e financeiras vivenciadas. Destaca-se que no momento da pesquisa não havia nenhum médico nos dois municípios do interior, situados, fora do litoral.

Os gestores municipais consideram os baixos salários, a falta de formação contínua, a impossibilidade de continuação da formação, as deficientes condições sociais e de trabalho nos municípios do interior, como determinantes para a recusa dos médicos à alocação ou transferência para os municípios ou seu abandono. Para os gestores de nível provincial a causa principal era o descumprimento do tempo previsto de permanência no município, estipulado normalmente para um ano, chegando os raros profissionais que aceitavam a transferência a permanecerem por mais de três anos no município. Destacam ainda o isolamento (longa distância da capital para os municípios) e as deficientes condições sociais e de trabalho.

Os médicos, por sua vez, mencionam o isolamento, as deficientes condições sociais e de trabalho, a impossibilidade de fazer negócios, entendida também como impossibilidade de adoção do regime de múltiplo emprego, os salários ruins e a impossibilidade de continuação da formação.

Para que aceitem trabalhar nos municípios do interior por um tempo não superior a dois anos, seriam necessárias, segundo os médicos, as seguintes condições: moradia gratuita no município, transporte para os profissionais e para os doentes, incentivos financeiros e materiais, melhoria das condições de trabalho e colocação nos municípios em questão de profissionais de outras categorias, com a devida capacitação técnica. 
Os médicos manifestam a sua insatisfação com as deficientes condições de trabalho consubstanciadas na insuficiência de meios de diagnóstico, medicamentos e insumos, deficiente organização do sistema de acolhimento e atendimento de doentes, insuficiência de meios de transporte para o pessoal e doentes, e pouca presença de agentes dos serviços de guarnição. Os alocados nos municípios reclamam também da insuficiência de $\mathrm{RH}$ especializados incluindo os de enfermagem. Segundo eles, os médicos especialistas seriam importantes no tratamento de doenças e para a troca de experiências.

A maioria dos médicos e gestores municipais se manifestou satisfeita com a formação. Entretanto, parece existir uma interligação entre a idade e a satisfação com a formação, pois os médicos sem pós-graduação e com idade inferior a quarenta anos manifestaram-se insatisfeitos com a formação, enquanto que aqueles com idade acima dos quarenta manifestaram-se de forma inversa. Portanto, avaliamos que há, provavelmente, certo conformismo com o nível de formação com o decorrer dos anos.

Os médicos nacionais referem que estão parcialmente satisfeitos com as condições sociais. Os gestores dos municípios mais distantes da cidade capital e que são técnicos de enfermagem (médio e superior) se manifestam insatisfeitos com as condições sociais. Um gestor municipal, entretanto, manifestou-se satisfeito com as condições sociais, por ter recebido à chegada ao município, um carro pessoal, uma moradia com quatro dependências e com todos os seus aparatos. O médico expatriado se manifestou satisfeito não só com as condições sociais, mas inclusive com todas as demais categorias. É importante contextualizar as falas do médico estrangeiro que depende da aprovação das instituições do poder local para continuar o seu contrato. Portanto, algumas das suas afirmações sobre as condições de trabalho e sociais e até sobre os salários parecem estar "superdimensionadas" até porque este grupo de expatriados se dedica, para a melhoria da sua condição de vida, ao pequeno comércio (informal), por exemplo, entre outras atividades com fins lucrativos.

Os gestores na sua totalidade referem que não se consegue atender a expectativa dos usuários. Quanto aos médicos, a maioria se manifestou satisfeita considerando o grande esforço individual que fazem para o atendimento dos pacientes, $o$ fato de os pacientes comparecerem às consultas de seguimento e porque os pacientes referem melhorias no seu estado de saúde, apesar das grandes dificuldades que enfrentam no exercício das suas atividades, considerando a insuficiência de médicos e as deficientes condições de traba- lho. Em média atendem 32 pacientes por cinco horas de consulta, quer de primeira, como de segunda consultas. Assim, o tempo médio de consulta dedicado a cada paciente é de 8,8 minutos. Para além dos doentes previamente marcados, atendem vários pedidos extras considerando a deficiente organização dos serviços de marcação de consultas e o fato das equipes de apoio permitirem esta prática. Assim, a média apurada pode não corresponder com a realidade.

Todos os gestores avaliam o programa de transferências temporárias de médicos aos municípios de forma negativa, considerando a recusa dos médicos para o cumprimento deste tipo de missão. Os gestores municipais referem que sempre que os médicos estão presentes nos municípios, o rendimento é regular. Esta avaliação consubstancia-se na pouca motivação dos referidos profissionais para o desempenho das suas atividades.

Na opinião de todos os gestores, os médicos estrangeiros têm bom desempenho. Isto se deve aos bons salários que recebem e às condições sociais a sua disposição, embora este desempenho pudesse ser melhor caso os mesmos fossem selecionados e recrutados diretamente pela DPSC ou pelos hospitais onde trabalham.

Os gestores de nível provincial avaliam o desempenho dos médicos nacionais como sendo regular, considerando que o reduzido número de médicos e as deficientes condições de trabalho tornam impossível um bom desempenho. Acrescentam que muitos dos médicos nacionais, mesmo não sendo especialistas, muitas vezes realizam o trabalho destes, para suprir algumas lacunas dos serviços hospitalares.

Entre os motivos mencionados pelos médicos para a aceitação de alocação na província, destacam-se: apoio do governo da província na fase de formação, estar próximo da família e do seu povo e o hospital provincial ter a especialidade da sua preferência.

Os principais fatores que interferem na qualidade da assistência médica, segundo os entrevistados, são: os baixos salários; a insuficiência de $\mathrm{RH}$; a alta rotação/rotatividade dos profissionais, ocasionando a descontinuidade assistencial; as precárias condições de trabalho e sociais; a falta de formação contínua e de cursos de pós-graduação. Na opinião dos entrevistados, as ações que poderiam contribuir para a melhoria da qualidade da assistência médica em Cabinda, ordenados por semelhança e número de citações, são: (1) formação de quadros angolanos na fase de graduação e pós-graduação, (2) melhoria das condições de trabalho, (3) admissão, a curto prazo, de mais médicos, (4) melhoria dos salários, (5) formação contínua que seja abrangente às mais 
diversas especialidades, (6) alocação na província e nos municípios de profissionais de outras categorias, (7) aumento dos recursos financeiros destinados aos hospitais, (8) melhoria das condições sociais, (9) trabalho igual, salário igual, (10) implementação de um programa de saúde rural, (11) incremento de ações de caráter preventivo e de forma particular, as ações de informação, educação e comunicação, (12) abertura de uma universidade na província que considere a pósgraduação das especialidades médicas como prioridade e (13) aumento do número de instituições sanitárias na província.

\section{Discussão}

Todos os gestores entrevistados referem que a rede pública de saúde de Cabinda não consegue atender a expectativa dos usuários considerando as deficientes condições de trabalho e o reduzido número de profissionais médicos. Estes fatores estão na base das constantes transferências de pacientes para o HCC que, por sua vez, sofre com insuficiência de médicos, deficientes condições técnicas e materiais e insuficiência de espaço para internações.

As condições referidas pelos médicos para a aceitação em trabalhar nos municípios do interior, por um tempo não superior a dois anos, coincidem com os fatores encontrados na literatura, referidos por Borelli 13, e que influenciam na rotatividade e retenção de profissionais nas zonas rurais: (a) fatores profissionais - natureza do trabalho, satisfação profissional, condições de trabalho, remuneração, oportunidades de crescimento profissional, acomodações físicas, entre outros; (b) fatores sociais - características pessoais e familiares; (c) fatores externos - relacionados com a comunidade e sua localização geográfica.

O problema da distribuição não eqüitativa de RH em saúde, ocasionando a baixa oferta de serviços em áreas distantes das zonas urbanas é um fenômeno de ordem mundial, apesar das especificidades relacionadas às diferentes realidades 11 . Neste sentido, diferentes estratégias têm sido implementadas por diferentes países na tentativa de garantir acesso aos serviços de saúde às populações das áreas rurais e remotas. Algumas destas estratégias foram analisadas tendose considerado que a experiência do Programa de Interiorização do Trabalho de Saúde (PITS) 10 do Brasil é a mais interessante para a realidade de Cabinda, pois concilia os aspectos da motivação intrínseca e extrínseca devendo ser ajustado aos objetivos e às especificidades econômicas e sócio-culturais locais. Os fatores extrínsecos se referem aos salários, benefícios sociais, tipo de chefia ou supervisão, condições físicas de trabalho, políticas organizacionais, clima de relações entre a direção e o indivíduo e regulamentos internos. Os fatores intrínsecos relacionam-se com o conteúdo do cargo ou com natureza das tarefas que o indivíduo executa e englobam os sentimentos de auto-realização, de crescimento individual e de reconhecimento profissional 14.

O PITS 10 é um programa transitório que visa atender às populações de municípios desprovidos de ou com precários serviços médico-sanitários, mediante a rotação de profissionais em seus territórios, aos quais se oferecem incentivos financeiros e de formação profissional.

Não existindo nenhum plano estratégico ou políticas de interiorização, alocação e retenção de médicos na província e nos municípios, em particular, o PITS poderia servir de base para a formulação de estratégias locais neste domínio.

Os apoios e incentivos a serem atribuídos poderiam variar consoante a distância que separa o município da capital da província, de município para município e consoante o grau de obtenção ou não dos resultados esperados. A mesma estratégia serviria também para o nível provincial, com as devidas adaptações.

A gestão dos problemas de saúde no nível rural tem aspectos muito particulares e deve ser objeto de atenção especial, particularmente para meios com dificuldades de comunicação e transporte. Os profissionais e a comunidade têm a percepção de que a prática de assistência médica rural é um heróico médico lutando para servir uma população dispersa, trabalhando inclusive finais de semana e sem uma estrutura hospitalar correspondente 9 . Esta observação coincide com a situação de várias localidades do interior de Cabinda, agravada com as carências já mencionadas e alguma instabilidade político-militar residual, em alguns municipios.

No entanto, a chave da saúde rural está na provisão da força de trabalho, incluindo treinamento apropriado e educação, transporte, acesso aos serviços apropriados, financiamento e o custo para os pacientes ${ }^{8}$. Para estes autores, o recrutamento de profissionais de saúde para áreas rurais é sempre problemático, pois exige que estes se adaptem às novas condições de vida $\mathrm{e}$ de trabalho.

Uma das estratégias para alocar profissionais para as regiões rurais contempla a atração de estudantes de origem rural, considerando que a origem das pessoas influencia na sua adaptação ao local de trabalho ${ }^{8}$. Esta estratégia merece aqui destaque, por Cabinda ser uma província do interior e pelo fato de a quase totalidade de médicos angolanos e gestores da saúde ser natural da 
província. Portanto, a naturalidade pesou na decisão dos médicos de aceitar a alocação referindo que assim estariam próximos das famílias e com possibilidade de "ajudar o seu povo".

Entretanto, existem outras estratégias em diferentes regiões do mundo, que visam à garantia de oferta de serviços de saúde a populações moradoras de áreas do interior, de difícil acesso ou carentes. Dois modelos têm sido mais freqüentemente utilizados: a introdução do serviço civil obrigatório, como contrapartida do recém-formado ao gasto social comprometido com a sua graduação; ou a distribuição quase compulsória de postos de trabalho em regiões mais distantes, em sistemas de saúde com forte controle estatal sobre o mercado de trabalho 10.

Para o caso de Angola e da Província de Cabinda, em particular, os dois modelos são de difícil implementação, considerando a enorme escassez do grupo de profissionais médicos, a liberalização do mercado de trabalho e a falta de uma política de bolsas internas, o que poderia servir de base para a implementação do primeiro modelo, de serviço civil obrigatório.

Na rede pública de Cabinda estão alocados quatro médicos especialistas angolanos, o que perfaz uma média de um médico especialista angolano para 57.058 habitantes. Entretanto, a OMS identifica um limiar na densidade da força de trabalho, abaixo do qual não seria possível atingir os "objetivos do desenvolvimento do milênio" 1 . Com base nas referidas estimativas, no contexto e nos objetivos da rede de saúde da província, pode-se calcular as necessidades de alocação e formação de médicos especialistas angolanos e nesta base elaborar um programa provincial de pós-graduação.

A especialização deve ser um objetivo a ser alcançado na rede de Cabinda considerando o seu papel na garantia de competências e habilidades-chave para o trabalho. A busca deste desígnio deve-se também ao fato de a especialização tornar o profissional mais eficiente na resolução dos complexos problemas colocados em determinado campo de estudo 15.

A formação habilita os profissionais para um determinado ofício em diferentes níveis, mas não assegura a qualificação permanente para o enfrentamento da inovação tecnológica, superação de paradigmas, novas descobertas ou a multidimensionalidade das necessidades individuais e coletivas de saúde ou a abertura para novos perfis de atuação sócio-institucional 16 . Baseando-se neste pressuposto, programas de desenvolvimento profissional são determinantes para a manutenção e melhoria da qualidade das ações e serviços de saúde. Estes programas só existem, de forma incipiente no HCC, mas com pouca participação dos médicos nacionais ocupados em outras atividades, no quadro do regime de empregos múltiplos. Ainda assim, o referido programa não é extensivo aos profissionais alocados nos municípios.

Nesta perspectiva, o pólo de formação permanente do HCC poderia ser transformado em pólo provincial, no sentido de garantir acesso a todos os médicos da província às ações de capacitação e atualização. A busca de consensos quanto à carga horária e ao conteúdo programático deveria ser uma das preocupações dos gestores das referidas ações formativas. Outros incentivos também poderiam ser estudados para atrair os médicos nacionais.

A acessibilidade é a capacidade de o paciente obter cuidado de saúde, de maneira fácil e conveniente, onde e quando necessitar 17. Embora Cabinda apresente o melhor índice de médico/ habitante, quando comparado com a média do país, de 1 médico para 20 mil habitantes 2 , parte significativa da população enfrenta dificuldades de acesso ao atendimento médico. Verificam-se longas filas de espera nos serviços de emergência e ambulatoriais e nos centros de saúde, a maioria desprovidos de médicos e de condições de trabalho, o que afeta a qualidade dos serviços, determinada pelas necessidades e expectativas dos clientes internos e externos 18. Verificam-se também elevadas taxas de morbi-mortalidade.

$\mathrm{O}$ relato dos médicos que referem atender a expectativa dos usuários contrasta não só com as constatações acima mencionadas, mas também com a sua grande insatisfação em relação às condições de trabalho e aos incentivos não condizentes com o esforço que fazem.

Em muitos sistemas de saúde, o tempo impõe a qualidade de cuidados prestados aos pacientes. Estudos em diferentes países sugerem que à medida que a carga de trabalho do médico aumenta, diminui o tempo por consulta 19. Esta parece ser a explicação para o reduzido tempo de duração da consulta no caso estudado. Para Sousa 19, com o qual concordamos, o tempo de consulta não deve ser limitado à tarefa de estabelecimento de uma relação de escuta, de compreensão e de negociação entre o médico e o paciente. Deve implicar também tempo suficiente para a realização de atividades de promoção, de prevenção, de detecção precoce de certas doenças, entre outras.

Os médicos destacam que os profissionais que se encontram em cursos de pós-graduação, considerada fator importante de qualidade, o fazem por conseguirem individualmente a saída do país. Há, portanto, necessidade de uma política de apoio à formação mais incisiva que considere a pós-graduação com uma das suas prioridades, 
o que permitiria, com o tempo, a substituição dos especialistas estrangeiros por angolanos.

De acordo com a Associação de Estudantes, os 15 graduandos enfrentam enormes dificuldades materiais e financeiras. Todos assumem, contudo, o compromisso de retornarem à província no fim da formação, confirmando deste modo o quanto o recrutamento local de candidatos para formação pode contribuir para o recrutamento e retenção de profissionais nas localidades do interior, como províncias, municípios e comunas, concomitante com uma política de bolsas internas.

Segundo os entrevistados, o fato de a província ter apoiado a formação foi um fator importante para a aceitação da alocação na província. Isto também demonstra que um programa de bolsas internas poderia ajudar na redução do déficit de médicos na província.

Cabinda registra, além da escassez de profissionais e a sua má distribuição, um grande déficit de leitos hospitalares e estruturas de saúde, sendo o problema mais acentuado na periferia e no interior da província. Assim, o acesso aos cuidados médicos é relativamente mais fácil para os habitantes urbanos e com custos de acesso mais baixos, quando comparados com os habitantes de áreas rurais, onde a distância a percorrer para o efeito é maior. A construção e reabilitação de estruturas, embora em curso, ainda não correspondem com as necessidades. Deveriam ser intensificados o ritmo e o investimento, neste âmbito, baseados no planejamento estratégico e tendo como princípios a eqüidade e a integralidade das ações.

A diferença salarial, de incentivos e benefícios entre profissionais, inclusive entre expatriados da mesma categoria, é um dos principais problemas da rede estudada. Entretanto, são comuns dois tipos básicos de política internacional de remuneração: políticas baseadas no país de origem e políticas baseadas no país hospedeiro 7. Os dois tipos, entretanto, oferecem vantagens e desvantagens. Contudo, a eqüidade salarial interna que pressupõe salários justos e adequados deveria ser uma das preocupações, considerando a necessidade de a rede dispor de médicos expatriados competentes, com facilidade de adaptação ao contexto sócio-lingüístico local e com dedicação exclusiva aos serviços, bem como a necessidade de motivação dos médicos angolanos que reclamam dos baixos salários. Como observado, a facilidade de adaptação do profissional ao contexto sócio-lingüístico e o desequilíbrio salarial têm reflexos na coesão das equipes, na aceitabilidade do cuidado pelo usuário e conseqüentemente na qualidade do atendimento médico. Nesta base e devido à complexidade da questão, avaliamos ser necessário um estudo aprofundado sobre a temática.

A contratação dos profissionais estrangeiros deveria ser precedida de um processo seletivo avaliando-se, entre outros, a competência, a experiência profissional e adaptabilidade às condições de trabalho e sócio-culturais. Para tanto, seria necessário algum envolvimento dos organismos interessados no processo, hospitais e direções de saúde, por serem detentores de informações sobre suas condições e necessidades da força de trabalho.

\section{Conclusão}

A discussão sobre força de trabalho em saúde é complexa e envolve desde a dimensão relacionada à qualificação até a distribuição segundo as necessidades, questões de financiamento, alocação, motivação, aceitabilidade da população, sobretudo numa região com grande diversidade e especificidades culturais.

Para o caso de Angola, é importante considerar o contexto específico de formação, recrutamento e alocação de técnicos em enfermagem e a incorporação de parteiras no atendimento em saúde para uma discussão mais fundamentada sobre o assunto, o que não foi alvo do estudo.

De todo o modo, os resultados da pesquisa e a discussão aqui produzida levam-nos a concluir que a gestão dos RH em saúde é determinante para a manutenção e melhoria da qualidade das ações e serviços de saúde, o que só é possível com ações coordenadas e permanentes das autoridades governamentais e sanitárias, dos gestores da rede, do pessoal clínico e dos usuários, coerente com o relatório da OMS ${ }^{1}$ que observa que "estratégias eficazes exigem que todos os atores e organizações relevantes trabalhem juntos". 


\section{Resumo}

Este artigo apresenta os resultados de uma pesquisa sobre a força de trabalho médica na rede pública de saúde da Província de Cabinda, República de Angola. O objetivo foi estudar as características dos recursos humanos médicos, visando contribuir para o desenho de estratégias para melhorar o acesso e a qualidade de assistência médica. O período do estudo foi de 2001 a 2004 e utilizou-se de dados secundários, entrevistas com profissionais e gestores, com roteiro semi-estruturado, observação direta e discussão com a literatura sobre o assunto. Constatou-se que a qualidade da assistência médica em Cabinda é baixa, com um índice médico/habitante de um médico para 3.356 habitantes. Em algumas localidades não existe nenhum médico sequer para uma comunidade de mais de $35 \mathrm{mil}$ habitantes, além das deficientes condições de trabalho e a pouca motivação dos profissionais. O estudo concluiu que a formulação e a implementação de políticas que visam à melhoria da gestão dos profissionais do setor podem contribuir para o aumento da qualidade da assistência médica na província, mas é necessário o envolvimento dos atores relevantes e pesquisas sobre outros grupos profissionais.

Pessoal de Saúde; Administração de Recursos Humanos em Saúde; Qualidade da Assistência à Saúde

\section{Colaboradores}

M. S. Oliveira participou da coleta, análise dos dados e redação do artigo. E. Artmann colaborou no desenho da pesquisa, análise dos dados e redação do artigo.

\section{Referências}

1. Organização Mundial da Saúde. Trabalhando juntos pela saúde: relatório mundial da saúde 2006. Versão preliminar. http://www.who.int/eportu guese/relatorio_m_saude_2006.pdf (acessado em 27/Jul/2008).

2. Oliveira MS. Assistência médica na rede pública de Cabinda/República de Angola: como melhorar a qualidade a partir da gestão de quadros médicos [Dissertação de Mestrado]. Rio de Janeiro: Escola Nacional de Saúde Pública, Fundação Oswaldo Cruz; 2005.

3. Ministério da Saúde. Lei no. 21-B/92. Lei de Bases do Sistema Nacional de Saúde de Angola. Diário da República 1992; 28 ago.

4. Ministério da Saúde. Plano Nacional de Desenvolvimento Sanitário (PNDS), 2006-2008. Luanda: Ministério da Saúde; 2005.
5. Vulnerability Analysis and Mapping, World Food Programme. Inquérito sobre segurança alimentar e modos de vida em meio rural no Planalto Central em Angola. http://www.sarpn.org.za/ documents/d0001762/Food_Security_Angola _June2005_Portugese.pdf (acessado em 21/ Abr/2007).

6. Governo da Província de Cabinda. Dados demográficos da Província de Cabinda, 2002. Cabinda: Governo da Província de Cabinda; 2002.

7. Dessler G. Administração de recursos humanos. São Paulo: Editora Pearson; 2003.

8. Wakerman J, Humphreys JS. Rural health: why it matters. Med J Aust 2002; 176:457-8.

9. MacIsaac P, Snowdon T, Thompson R, Wilde T. Case management: a model for recruitment of rural general practitioners. Aust J Rural Health 2000; 8:111-5. 
10. Seixas PHD'A, Stella RCR. Médicos e mercados de trabalho: experiências de interiorização, estímulos e alternativas de fixação. In: Negri B, Faria R, Viana ALd'A, organizadores. Recursos humanos em saúde: política, desenvolvimento e mercado de trabalho. São Paulo: Núcleo de Estudos de Políticas Públicas, Universidade Estadual de Campinas; 2002. p. 345-71.

11. Castro JL, Vilar RLA. Desafios e estratégias para a interiorização do trabalho em saúde. In: Santana JP, Campos FE, organizadores. Política de recursos humanos em saúde. v. 1. Brasília: Ministério da Saúde; 2002. p. 179-84.

12. Donabedian A. The seven pillars of quality. Arch Pathol Lab Med 1990; 114:1115-8.

13. Borelli FRG. A rotatividade dos profissionais de saúde na zona rural de Sergipe: um problema a ser enfrentado [Dissertação de Mestrado]. Rio de Janeiro: Escola Nacional de Saúde Pública, Fundação Oswaldo Cruz; 2004.

14. Cunha MP, Rego A, Cunha RC, Cabral-Cardoso C. Manual do comportamento organizacional e gestão. 1ạ Ed. Lisboa: Editora RH; 2003.
15. Bevilacqua RG, Sampaio SAP. As especializações: histórico e projeções. In: Negri B, Faria R, Viana ALd'A, organizadores. Recursos humanos em saúde: política, desenvolvimento e mercado de trabalho. São Paulo: Núcleo de Estudos de Políticas Públicas, Universidade Estadual de Campinas; 2002. p. 33-90.

16. Ceccim RB. Formação e desenvolvimento na área da saúde: observação para a política de recursos humanos. In: Ministério da Saúde, organizador. Observatório de recursos humanos em saúde no Brasil: estudos e análises. Rio de Janeiro: Fundação Oswaldo Cruz; 2003. p. 373-413.

17. Donabedian A. The quality of care. How can it be assessed? J Am Med Assoc 1988; 260:1743-8.

18. Malagón-Londoño G. O universo do hospital. In: Malagón-Londoño G, Galán-Moreira R, PontónLaverde G. Administração hospitalar. 2a Ed. Rio de Janeiro: Editora Guanabara Koogan; 2003. p. 9-12.

19. Sousa JC. Quanto tempo é tempo bastante? Revista Portuguesa de Clínica Geral 2006; 22:549-53.

Recebido em 16/Abr/2008

Versão final reapresentada em 18/Ago/2008

Aprovado em 08/Out/2008 